\title{
Donor lung salvage after neurogenic pulmonary edema with the use of post-transplant extracorporeal membrane oxygenation
}

\author{
Steven M. Fiser, MD, Irving L. Kron, MD, Stewart M. Long, MD, Aditya K. Kaza, MD, Mark Robbins, MD, \\ John A. Kern, MD, and Curtis G. Tribble, MD, Charlottesville, Va
}

$\mathrm{D}$ evelopment of neurogenic pulmonary edema can prevent the use of donor lungs for transplantation. We present a case in which severe preoperative donor neurogenic pulmonary edema was overcome after transplantation with the use of extracorporeal membrane oxygenation.

\section{Clinical Summary}

Donor. A 17-year-old child was pronounced dead after a gunshot wound to the head. Soon after consent for organ donation had been obtained from the family, significantly worsening oxygenation was noted despite diuretics and pulmonary therapy (Table 1). The initial trauma chest $\mathrm{x}$-ray film was clear; however, a follow-up chest $\mathrm{x}$-ray film was consistent with the development of severe pulmonary edema in both lungs. During this period, the mean blood pressure was at least $65 \mathrm{~mm} \mathrm{Hg}$, extensive fluid resuscitation was not necessary, and a drug screen was negative. Thus, it was believed that the donor's pulmonary edema was neurogenic in origin.

Recipient. A 55-year-old woman had severe pulmonary fibrosis: forced expiratory volume in 1 second of $0.71 \mathrm{~L}$ and forced vital capacity of $0.85 \mathrm{~L}, 33 \%$ and $30 \%$ of predicted, respectively; room air blood gas $\mathrm{pH}, 7.40 ; \mathrm{PCO}_{2}, 48 \mathrm{~mm} \mathrm{Hg}$; and $\mathrm{Po}_{2}, 53 \mathrm{~mm} \mathrm{Hg}$. This patient required $5 \mathrm{~L}$ of oxygen to maintain an oxygen saturation of $88 \%$. Her survival without a transplant was estimated to be less than 3 months. The patient arrived at our facility shortly after the donor became available. After arrival, she was noted to be profoundly dyspneic while breathing $5 \mathrm{~L}$ of oxygen and was believed to have had an even further decline in pulmonary function compared with her last evaluation.

Because this might be the recipient's only chance to undergo lung transplantation, a conference was held with the recipient and her family. After extensive discussions, the decision was made to

From the Department of Thoracic and Cardiovascular Surgery, University of Virginia Health Sciences Center, Charlottesville, Va.

Received for publication March 16, 2001; accepted for publication April 12,2001

Address for reprints: Curtis G. Tribble, MD, Department of Thoracic and Cardiovascular Surgery, University of Virginia, Health Sciences Center, Box 3111, MR4 Building, Charlottesville, VA 22908 (E-mail: ctribble@ virginia.edu).

J Thorac Cardiovasc Surg 2001;122:1257-8

Copyright (๑) 2001 by The American Association for Thoracic Surgery

$0022-5223 / 2001 \$ 35.00+0 \quad \mathbf{1 2 / 5 4 / 1 1 6 4 6 4}$

doi:10.1067/mtc.2001.116464 proceed with the operation despite the development of rapidly progressing pulmonary edema in the donor. Preoperatively, the patient was informed of the tentative plan to proceed with extracorporeal membrane oxygenation (ECMO) after the transplant operation to allow time for the donor lungs to recover.

The donor was taken to the operating room. After a median sternotomy, pulmonary artery alprostadil injection, and EuroCollins solution flush, the heart-lung block was harvested without difficulty. The lungs and heart were then separated. The recipient meanwhile underwent a median sternotomy followed by institution of cardiopulmonary bypass. The patient underwent right lung transplantation first with a total ischemic time of 45 minutes. The left lung was then transplanted with a total ischemic time of 90 minutes. After ventilation and perfusion of both lungs, a trial off cardiopulmonary bypass was attempted. During this trial, the patient had extremely poor oxygenation as a result of the severely edematous lungs (Table 2). ECMO was instituted in the operating room with the use of a central venous-pulmonary artery circuit. The patient was then transferred to the intensive care unit. Oxygenation on ECMO is shown in Table 2. The patient was weaned from ECMO after 2 days and was discharged to her home on hospital day 38. Early follow-up pulmonary function tests on this patient demonstrated excellent lung function: forced expiratory volume in 1 second, $1.95 \mathrm{~L}$ (96\%); forced vital capacity, $2.37 \mathrm{~L}$ (87\%); and total lung capacity, $2.96 \mathrm{~L}$ (72\%). The patient has good pulmonary function and has minimal exercise limitation.

\section{Discussion}

Neurogenic pulmonary edema can occur after brain injury, seizure, hydrocephalus, or brain death and can result in significant pulmonary dysfunction. ${ }^{1}$ Despite extensive investigations, the mechanisms involved in the development of neurogenic pulmonary edema are not completely understood. One theory suggests that central mechanisms alter pulmonary endothelial permeability, leading to an increase in lung edema formation. ${ }^{2}$ Another theory supports the view that high intravascular pressures, possibly as a result of catecholamine release, directly damages pulmonary endothelium and leads to subsequent edema formation. ${ }^{3}$ Finally, some have suggested that a transient elevation in left-sided cardiovascular pressures or vasoconstriction contributes to the development of pulmonary edema. ${ }^{1}$ Mortality for patients with neurogenic pulmonary edema is over $50 \%$ in some series. However, this was related to the neurologic dysfunction and not the respiratory failure. ${ }^{1}$

Given that the neurogenic pulmonary edema was likely reversible and that the native pulmonary function of the recipient was deteriorating rapidly, we believed the best decision was to proceed with 
TABLE 1. Donor management

\begin{tabular}{rlccc}
\hline Time & $\mathrm{FiO}_{2}$ & $\mathrm{PEEP}\left(\mathrm{cm} \mathrm{H}_{\mathbf{2}} \mathbf{0}\right)$ & $\mathbf{P 0}_{\mathbf{2}}(\mathbf{m m ~ H g})$ & $\mathbf{P 0}_{2} / \mathrm{FlO}_{2}$ ratio \\
\hline 0 & 1 & 5 & 414 & 414 \\
700 & 1 & 10 & 359 & 359 \\
1400 & 0.7 & 5 & 94 & 133 \\
\hline
\end{tabular}

$\mathrm{FIO}_{2}$ Inspired oxygen fraction; $\mathrm{PEEP}$, positive end-expiratory pressure; $\mathrm{PO}_{2}$ oxygen tension.

transplantation. This decision was made with the understanding that the recipient would almost certainly initially have severe oxygenation difficulties that could be temporarily overcome with the use of ECMO. Ventilatory support would allow time for the lungs to recover from the neurogenic pulmonary edema that occurred in the donor. We and others have used ECMO after lung transplantation with some success. At our institution, a total of 10 lung transplant recipients required postoperative ECMO, of whom 4 (40\%) have survived. ${ }^{4}$ Meyers and associates ${ }^{5}$ recently reported on 12 patients requiring ECMO after lung transplantation. Overall survival in that study was $58 \%$ (7/12). We believe, however, that this is the first reported successful use of ECMO in a recipient receiving lungs from a donor with severe preoperative neurogenic pulmonary edema.

In summary, neurogenic pulmonary edema can be an impediment to the use of donor lungs for transplantation. This process can be temporarily overcome with the use of ECMO, which allows time for the donor lungs to recover. Although we would not recommend the routine use of lungs with neurogenic pulmonary edema, consideration should be given to using lungs with this type of dysfunction in recipients who are unlikely to survive long enough for another donor to become available.
TABLE 2. Recipient management

\begin{tabular}{|c|c|c|c|}
\hline Date & Time & Support & $\begin{array}{c}\text { Arterial } \\
\text { blood gases* }\end{array}$ \\
\hline \multirow[t]{4}{*}{ May 20} & 1850 & Off CPB & $7.31 / 49 / 72$ \\
\hline & 1910 & Off CPB & $7.28 / 53 / 53$ \\
\hline & 1918 & On CPB & \\
\hline & 2020 & On ECMO, $\mathrm{FIO}_{2}=1.0$ & $7.47 / 29 / 570$ \\
\hline \multirow[t]{2}{*}{ May 21} & 3 & On ECMO, $\mathrm{FIO}_{2}=0.45$ & $7.34 / 26 / 169$ \\
\hline & 2000 & On ECMO, $\mathrm{FlO}_{2}=0.45$ & $7.52 / 23 / 255$ \\
\hline \multirow[t]{2}{*}{ May 22} & 700 & On ECMO, $\mathrm{FIO}_{2}=0.21$ & $7.44 / 28 / 233$ \\
\hline & 1248 & Off ECMO, Vent. $\mathrm{FIO}_{2}=1.0$ & $7.46 / 36 / 182$ \\
\hline
\end{tabular}

$C P B$, Cardiopulmonary bypass; ECMO, extracorporeal membrane oxygenation; Vent., ventilator.

${ }^{*} \mathrm{pH}, \mathrm{PCO}_{2}(\mathrm{~mm} \mathrm{Hg}), \mathrm{P}_{2}(\mathrm{~mm} \mathrm{Hg})$.

\section{References}

1. Smith WS, Matthay MA. Evidence for a hydrostatic mechanism in human neurogenic pulmonary edema. Chest. 1997;111:1326-33.

2. McClellan MD, Dauber IM, Weil JV. Elevated intracranial pressure increases pulmonary vascular permeability to protein. J Appl Physiol. 1989;67:1185-91.

3. Theodore J, Robin ED. Speculations on neurogenic pulmonary edema. Am Rev Respir Dis. 1976;113:405-11.

4. Fiser SM, Kron IL, Long SM, Kaza AK, Kern JA, Tribble CG. Early intervention following severe oxygenation index elevation improves survival following lung transplantation. J Heart Lung Transplant. 2001;20:631-6.

5. Meyers BF, Sundt TM, Henry S, Trulock EP, Guthrie T, Cooper JD, et al. Selective use of extracorporeal membrane oxygenation is warranted after lung transplantation. J Thorac Cardiovasc Surg. 2000;120:20-8. 